\title{
Evaluation of Core Residence Time of Fuel Cruds from Hanul Unit 1 Cycle 17
}

\section{한울1호기 17 주기 연료 크러드의 노내 체류시간 평가}

\author{
Doo Ho Lee \\ KHNP Central Research Institute, 1312-70, Yuseong-daero, Yuseong-gu, Daejeon, Korea \\ 이두호 \\ 한수원중앙연구원, 대전광역시 유성구 유성대로 1312 번길 70
}

(Received September 3, 2014 / Revised September 22, 2014 / Approved September 30, 2014)

\begin{abstract}
Corrosion products are released to the primary coolant in the corrosion process of structural materials. They are deposited on fuel surfaces and activated on exposure to a neutron flux with formation of radionuclides that can become incorporated into out-of-core surface films. To get a clear understanding of activated crud formation process, the specific activity and core residence time of fuel cruds was calculated as a function of exposure time to the core neutron flux on the assumption that parent nuclide is being deposited continuously. Fuel cruds were sampled in the fuel scraping campaign from Hanul Unit 1 Cycle 17 and analyzed for elemental concentration and radioisotope activity.
\end{abstract}

Keywords: Corrosion product, Fuel crud, Core residence time, Specific activity

발전소 구조재료의 일반부식에서 기인된 부식생성물은 연료 표면에 침적되어 방사화되고, 다시 노외로 방출되어 계통 선량 율을 증가시킨다. 본 연구에서는 방사화된 크러드의 생성과정에 대한 이해를 높이고자 연료 크러드의 비방사능 값과 노내 체류시간을 계산하였다. 노내 체류시간 계산시 모핵종이 조사기간 동안 지속적으로 일정한 양만큼 침적되는 것으로 가정하 였다. 본 연구에 활용된 연료 크러드 시료는 한울1호기 17차 $\mathrm{O} / \mathrm{H}$ 시 fuel scraping을 통해 채취되었으며, 본 연구를 위해 원 소성분 분석과 핵종 분석이 수행되었다.

중심단어: 부식생성물, 연료 크러드, 노내 체류시간, 비방사능

* Corresponding Author.

Doo Ho Lee, KHNP Central Research Institute, E-mail: dooholee@khnp.co.kr, Tel: +82-42-870-5453

1. 서론

일차계통 냉각재의 부식생성물(corrosion product)은 증 기발생기 전열관 및 각종 배관의 일반부식으로부터 기인되 어 일부는 냉각재로 용출된 후 핵연료 계통에서 냉각재와 피 복관과의 온도차에 따른 용해도 차이에 의해, 또는 입자성 부 식생성물과 연료 피복관 표면과의 비탄성 충돌에 의한 물리 적인 침적 메커니즘에 의해 연료 표면에 침적된다. 연료 표 면에 침적된 크러드(crud)는 일정 기간 동안 노내에 체류하
면서 중성자 조사에 의한 방사화 과정을 통해 방사능을 띠게 되고, 다시 냉각재로 용출되어 증기발생기 표면 또는 계통 배 관의 표면 산화막으로 재분배되면서 일차계통의 선량율 증 가를 유발하게 된다. 따라서 일차계통의 선량율이 축적되는 과정을 정확히 모델링하기 위해서는 크러드의 연료 침적과 노내 체류시간, 크러드의 노외 방출 및 일차계통 침적 등에 관한 종합적인 정보들을 필요로 한다. 이중 크러드의 연료 및 계통 침적 메커니즘 등에 대해서는 다양한 연구 $[1,2,3]$ 들이 시도된 바 있으나, 크러드의 노내 체류 시간에 대한 연구는 
최근까지도 매우 부족한 실정인데, 이는 연료 크러드의 채취 및 분석이 극히 제한적으로만 시행되기 때문이다.

통상적으로 연료 크러드는 연료 초음파 세정(Ultrasonic Fuel Cleaning) 또는 Fuel Scraping을 통해 채취될 수 있다. 하지만 연료 초음파 세정 시에 채취되는 크러드 시료는 각 Span별 크러드 분포에 관한 구체적인 정보를 제공하지 못 한다. 이는 연료 초음파 세정이 연료의 특정 Span의 정해 진 구간에서만 이루어지는 것이 아니기 때문이다. 반면 Fuel Scraping을 통해 채취된 연료 크러드 시료는 각 Span별 크러 드 분포 및 노내 체류시간에 대한 직접적인 정보를 제공해주 지만, 많은 경비가 소요되므로 특별한 목적 이외에는 잘 활 용되지 않는다. 국내에서는 한울1호기 17 주기 아연주입 운 전 후의 주입효과 평가를 위하여 2010년 9월, 한울1호기 사 용후연료저장조에서 국내 최초로 Fuel Scraping 시료채취 및 분석을 시행한 바 있다(Fig. 1).

본 논문에서는 한울 1 호기 17 차 $\mathrm{O} / \mathrm{H}$ 시에 채취된 연료 크 러드 시료를 활용하여 크러드의 비방사능 농도 및 노내 체류 시간을 계산한 결과를 기술하였다.

\section{2. 본론}

\section{1 연료 크러드 시료 채취}

한울1호기는 2009년 3월 24일 원자로 임계에 도달된 이 후 2010년 8월 28일 발전 정지되었다. 연료 크러드 시료는 2010년 9월 4일부터 9월 5일까지 이틀간 한울1호기 사용후 연료저장조에서 채취되었으며, 한울1호기 17주기에 연소된 연료 중 1회연소 2 다발, 2 회연소 1다발을 대상으로 총 63 개 가 채취되었다. 다음의 Table 1 은 크러드 시료가 채취된 연 료의 내역을, Fig. 2는 한울1호기 17 주기 연료집합체의 장전 위치를 보여준다.

연료 크러드 채취를 위해 먼저 X-Y 검사테이블에 크러 드 채취장치(Scraper)를 장착하고 공기 실린더 모터 작동에 의해 크러드 채취장치가 연료 특정부위 지점에 접근토록 한 후, $\mathrm{Al}_{2} \mathrm{O}_{3}$ 재질의 Scraper로 피복관 표면의 크러드를 긁어 흡 입용 펌프로 이송하여 시료필터에 채취하였다. 특히, 발전소 현장에서 크러드 시료를 채취할 때 연료 Face별로 육안검사 를 수행하여 크러드가 많이 보이는 연료 Face 3 면을 기준

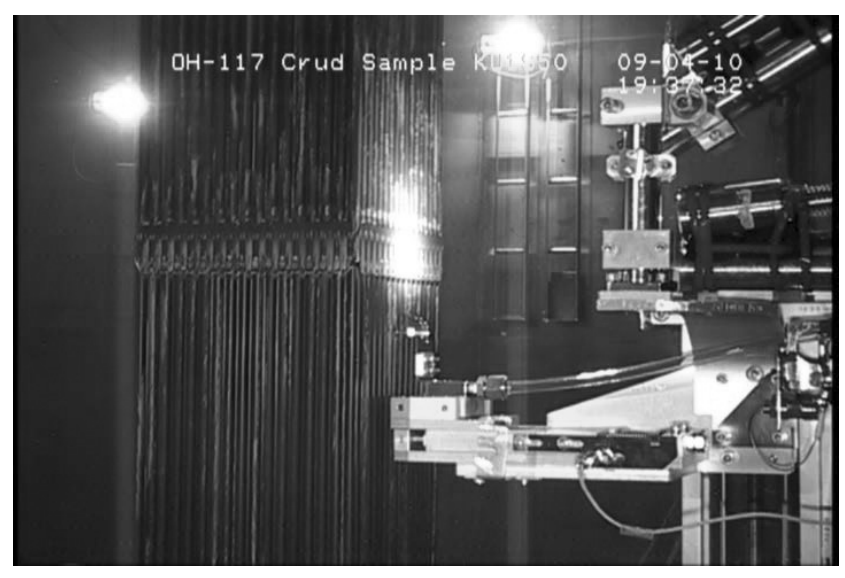

Fig. 1. Crud Scraping at Hanul Unit 1.

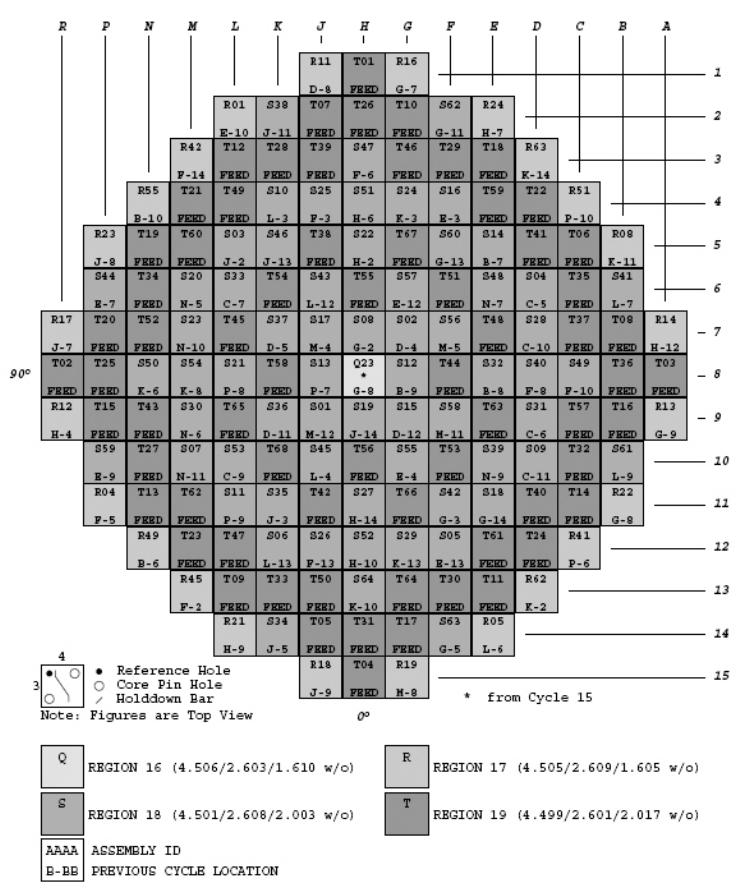

Fig. 2. Hanul Unit 1 Cycle 17 Core Map.

Table 1. Information on Scraped Assemblies of Hanul Unit 1

\begin{tabular}{ccc}
\hline Assembly & Burn-up (MWD/MTU) & Comments \\
\hline S50 & 45,879 & Twice-Burned \\
\hline T65 & 25,180 & Once-Burned \\
\hline T42 & 25,169 & Once-Burned \\
\hline
\end{tabular}




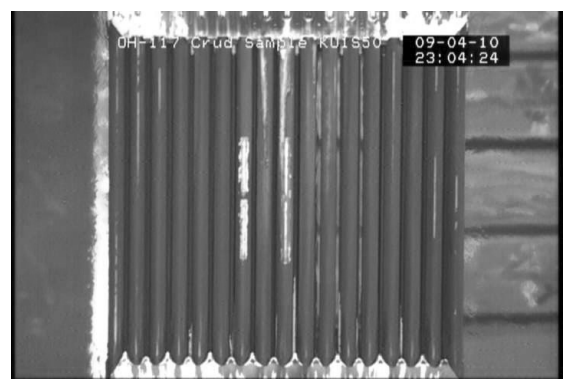

(A) $\mathrm{S} 50$

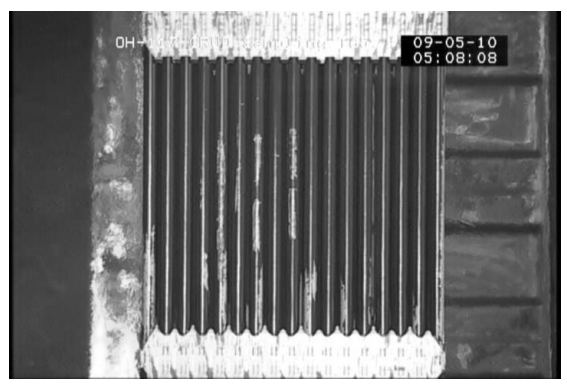

(B) T65

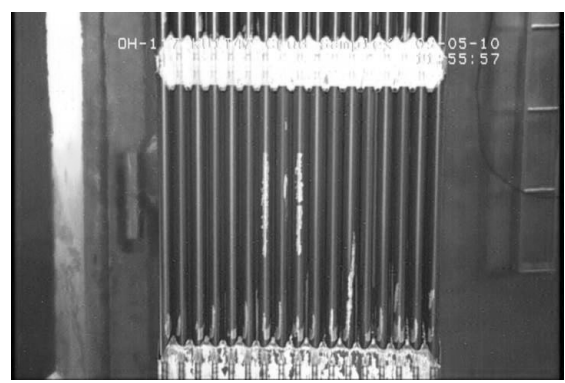

(C) T42

Fig. 3. Visual Inspection of Fuel Assemblies after Crud Scraping.

Table 2. Elemental Concentrations by ICP-AES ( $\mu \mathrm{g} /$ Filter) [4]

\begin{tabular}{ccccccccc}
\hline Filter & F/A & Rod & Span & B & Fe & Ni & $\mathrm{Cr}$ & $\mathrm{Zr}$ \\
\hline 8 & S50 & 9 & $5 \mathrm{~B}$ & 20.4 & 34 & 52 & 10.8 & 20.4 \\
\hline 10 & $\mathrm{~S} 50$ & 9 & $6 \mathrm{~A}$ & 50.4 & 284 & 228 & 22.8 & 52 \\
\hline 14 & $\mathrm{~S} 50$ & 7 & $6 \mathrm{~B}$ & 14.4 & 180 & 140 & 14.4 & 22 \\
\hline 35 & $\mathrm{~T} 65$ & 7 & $6 \mathrm{~B}$ & 78.8 & 5.6 & 10.4 & $<4.0$ & 9.6 \\
\hline 37 & $\mathrm{~T} 65$ & 7 & $6 \mathrm{~A}$ & 48.8 & 8.4 & 7.2 & 4 & 6.4 \\
\hline 39 & $\mathrm{~T} 65$ & 7 & $5 \mathrm{~B}$ & 107 & 16 & 17.2 & $<4.0$ & 8.4 \\
\hline 52 & $\mathrm{~T} 42$ & 9 & $6 \mathrm{~A}$ & 15.2 & 5.6 & 4.8 & $<4.0$ & 6 \\
\hline 54 & $\mathrm{~T} 42$ & 9 & $6 \mathrm{~B}$ & 11.2 & 14.1 & 20.4 & $<4.0$ & 11.6 \\
\hline 58 & $\mathrm{~T} 42$ & 7 & $6 \mathrm{~A}$ & 42.4 & 13.2 & $<4.0$ & 4 & 4.4 \\
\hline
\end{tabular}

으로 9번 연료봉과 7번 연료봉에 대해 각 Span별로 크러드 시료를 채취하였으며, 크러드 채취 후 연료별로 육안 검사를 수행한 결과 크러드 채취부에 별다른 손상 없이 크러드만 채 취된 상태임을 확인하였다. Fig. 3은 크러드 채취 후의 몇몇 연료봉의 상태를 보여주고 있다.

채취된 크러드 시료에 대해서는 SEM과 EPMA를 이용한 표면분석과 ICP-AES를 이용한 원소성분 분석, 감마핵종분석 기를 이용한 핵종 분석을 수행하였다. 본 논문에서는 연료 크러드의 노내 체류시간 계산을 위한 원소성분과 핵종 분석 결과만을 다루기로 한다.

\section{2 연료 크러드의 분석 결과}

한울1호기에서 채취된 연료 크러드의 일반적인 무게가
필터당 1 4 mg 수준이었으므로[4], 모든 시료에 대해 동일 한 분석방법을 적용할 순 없었다. 따라서 필터별로 선별하여 원소성분 분석과 방사화 핵종 분석을 실시하였으며, 그 결과 를 Table 2와 3에 각각 나타내었다. 이 때 방사화 핵종의 농도 는 연료 크러드가 채취된 시점이 아닌 발전소의 정지시점을 기준으로 보정한 값으로 표기하였다.

분석된 시료 모두 $\mathrm{Ni} / \mathrm{Fe}$ 의 값이 0.5 를 초과하였으며(평 균 1.06), 이는 니켈 페라이트 이외에도 $\mathrm{Ni}, \mathrm{NiO}$ 등의 화합물 이 존재함을 의미한다[5]. 한편 크러드의 원소성분으로 붕소 가 많이 검출되었으나, 이는 연료 크러드 시료가 채취되었던 사용후연료저장조 계통수에 의한 오염으로 해석된다.

\section{3 연료 크러드의 노내 체류시간 계산}

연료 크러드의 원소성분 및 방사화학적 조성자료를 활용 하면 연료 집합체의 시료채취 지점에서의 크러드의 노내 체 류시간 추정이 가능하다. 크러드의 노내 체류시간은 연료 크 러드가 노내에서 연속적인 중성자속(neutron flux)에 노출되 어 해당 비방사능 농도를 나타낼 때까지 방사화될 때의 소요 시간으로 정의될 수 있다.

먼저 부식생성물이 방사화되는 반응은 다음의 식으로 표 현할 수 있다.

$$
A=N\left(\sigma_{T} \phi_{T}+\sigma_{E} \phi_{E}+\sigma_{F} \phi_{F}\right)\left(1-e^{-\lambda t}\right)
$$

여기서, A : 방사능 농도 (dps)

$\mathrm{N}$ : 모핵종의 원자수

$\sigma$ : 중성자 포획단면적 $\left(\mathrm{cm}^{2}\right)$ 
Doo Ho Lee : Evaluation of Core Residence Time of Fuel Cruds from Hanul Unit 1 Cycle 17

Table 3. Gamma Spectroscopy Results ( $\mu$ Ci/Filter) (modified from Ref.[4])

\begin{tabular}{|c|c|c|c|c|c|c|c|c|c|}
\hline Filter & $\mathrm{F} / \mathrm{A}$ & Rod & Span & ${ }^{51} \mathrm{Cr}$ & ${ }^{54} \mathrm{Mn}$ & ${ }^{58} \mathrm{Co}$ & ${ }^{59} \mathrm{Fe}$ & ${ }^{60} \mathrm{Co}$ & ${ }^{65} \mathrm{Zn}$ \\
\hline 1 & S50 & 9 & 1 & $2.11 \mathrm{E}+00$ & $3.05 \mathrm{E}-01$ & $3.28 \mathrm{E}+00$ & $1.12 \mathrm{E}-01$ & $5.71 \mathrm{E}-01$ & $2.04 \mathrm{E}-02$ \\
\hline 2 & S50 & 9 & 2 & $1.30 \mathrm{E}+00$ & 2.13E-01 & $4.76 \mathrm{E}+00$ & 7.84E-02 & 4.11E-01 & $1.02 \mathrm{E}-02$ \\
\hline 3 & S50 & 9 & 3 & $4.09 \mathrm{E}+00$ & 4.37E-01 & $8.07 \mathrm{E}+00$ & $1.68 \mathrm{E}-01$ & $9.32 \mathrm{E}-01$ & $3.06 \mathrm{E}-02$ \\
\hline 4 & S50 & 9 & $4 \mathrm{~A}$ & $2.52 \mathrm{E}+00$ & $2.44 \mathrm{E}-01$ & $4.30 \mathrm{E}+00$ & $8.96 \mathrm{E}-02$ & $5.61 \mathrm{E}-01$ & $2.04 \mathrm{E}-02$ \\
\hline 5 & S50 & 9 & $4 \mathrm{~B}$ & $6.24 \mathrm{E}+00$ & $4.27 \mathrm{E}-01$ & $9.91 \mathrm{E}+00$ & $1.79 \mathrm{E}-01$ & $1.08 \mathrm{E}+00$ & $3.06 \mathrm{E}-02$ \\
\hline 18 & $\mathrm{~S} 50$ & 7 & $5 \mathrm{~B}$ & $1.95 \mathrm{E}+00$ & $1.83 \mathrm{E}-01$ & $4.08 \mathrm{E}-01$ & $5.61 \mathrm{E}-02$ & $3.91 \mathrm{E}-01$ & $1.02 \mathrm{E}-02$ \\
\hline 21 & S50 & 7 & $5 \mathrm{~A}$ & $1.37 \mathrm{E}+00$ & 1.12E-01 & $2.35 \mathrm{E}+00$ & 4.49E-02 & $2.71 \mathrm{E}-01$ & $1.02 \mathrm{E}-02$ \\
\hline 22 & $\mathrm{~T} 65$ & 9 & 1 & $2.21 \mathrm{E}+00$ & $3.15 \mathrm{E}-01$ & $3.41 \mathrm{E}+00$ & $1.12 \mathrm{E}-01$ & $5.92 \mathrm{E}-01$ & $2.04 \mathrm{E}-02$ \\
\hline 23 & T65 & 9 & 2 & $1.28 \mathrm{E}+00$ & $2.14 \mathrm{E}-01$ & $4.68 \mathrm{E}+00$ & $7.87 \mathrm{E}-02$ & 4.11E-01 & $1.02 \mathrm{E}-02$ \\
\hline 24 & T65 & 9 & 3 & $3.93 \mathrm{E}+00$ & 4.17E-01 & $7.73 \mathrm{E}+00$ & $1.57 \mathrm{E}-01$ & $8.92 \mathrm{E}-01$ & $3.06 \mathrm{E}-02$ \\
\hline 25 & T65 & 9 & $4 \mathrm{~A}$ & $2.52 \mathrm{E}+00$ & $2.44 \mathrm{E}-01$ & $4.29 \mathrm{E}+00$ & 8.99E-02 & $5.62 \mathrm{E}-01$ & $2.04 \mathrm{E}-02$ \\
\hline 26 & $\mathrm{~T} 65$ & 9 & $4 \mathrm{~B}$ & $6.27 \mathrm{E}+00$ & $4.27 \mathrm{E}-01$ & $9.94 \mathrm{E}+00$ & $1.80 \mathrm{E}-01$ & $1.08 \mathrm{E}+00$ & $3.06 \mathrm{E}-02$ \\
\hline 39 & T65 & 7 & $5 \mathrm{~B}$ & $2.09 \mathrm{E}+00$ & $1.93 \mathrm{E}-01$ & 4.42E-01 & $5.63 \mathrm{E}-02$ & $4.21 \mathrm{E}-01$ & $1.02 \mathrm{E}-02$ \\
\hline 42 & $\mathrm{~T} 65$ & 7 & $5 \mathrm{~A}$ & $1.30 \mathrm{E}+00$ & $1.02 \mathrm{E}-01$ & $2.21 \mathrm{E}+00$ & $4.51 \mathrm{E}-02$ & $2.51 \mathrm{E}-01$ & $1.02 \mathrm{E}-02$ \\
\hline 43 & $\mathrm{~T} 42$ & 9 & 1 & $2.16 \mathrm{E}+00$ & $3.05 \mathrm{E}-01$ & $3.35 \mathrm{E}+00$ & $1.13 \mathrm{E}-01$ & $5.72 \mathrm{E}-01$ & $2.04 \mathrm{E}-02$ \\
\hline 44 & $\mathrm{~T} 42$ & 9 & 2 & $1.36 \mathrm{E}+00$ & $2.24 \mathrm{E}-01$ & $4.97 \mathrm{E}+00$ & $7.90 \mathrm{E}-02$ & 4.31E-01 & $1.02 \mathrm{E}-02$ \\
\hline 45 & $\mathrm{~T} 42$ & 9 & 3 & $4.02 \mathrm{E}+00$ & $4.27 \mathrm{E}-01$ & $7.88 \mathrm{E}+00$ & $1.58 \mathrm{E}-01$ & $9.13 \mathrm{E}-01$ & $3.07 \mathrm{E}-02$ \\
\hline 46 & T42 & 9 & $4 \mathrm{~A}$ & $2.66 \mathrm{E}+00$ & $2.54 \mathrm{E}-01$ & $4.51 \mathrm{E}+00$ & $9.04 \mathrm{E}-02$ & 5.82E-01 & $2.04 \mathrm{E}-02$ \\
\hline 47 & $\mathrm{~T} 42$ & 9 & $4 \mathrm{~B}$ & $6.23 \mathrm{E}+00$ & $4.27 \mathrm{E}-01$ & $9.81 \mathrm{E}+00$ & $1.81 \mathrm{E}-01$ & $1.06 \mathrm{E}+00$ & $3.07 \mathrm{E}-02$ \\
\hline 60 & $\mathrm{~T} 42$ & 7 & $5 \mathrm{~B}$ & $1.89 \mathrm{E}+00$ & $1.73 \mathrm{E}-01$ & 4.00E-01 & $5.66 \mathrm{E}-02$ & $3.81 \mathrm{E}-01$ & $1.02 \mathrm{E}-02$ \\
\hline 63 & T42 & 7 & $5 \mathrm{~A}$ & $1.32 \mathrm{E}+00$ & $1.02 \mathrm{E}-01$ & $2.25 \mathrm{E}+00$ & 4.53E-02 & $2.51 \mathrm{E}-01$ & $1.02 \mathrm{E}-02$ \\
\hline
\end{tabular}

$\varphi$ : 중성자속 (neutron $/ \mathrm{cm}^{2}-\mathrm{s}$ )

$\lambda:$ 붕괴상수 $\left(\mathrm{sec}^{-1}\right)$

$\mathrm{t}$ : 노내 체류시간 $(\mathrm{sec})$
$\mathrm{S}$ : 비방사능 농도 $(\mathrm{Bq} / \mathrm{g})$

$\mathrm{AW}$ : 모핵종의 원자량 $(\mathrm{g})$

ai : 모핵종의 천연동위원소비

${ }^{(54} \mathrm{Mn}$ 모핵종인 ${ }^{54} \mathrm{Fe}$ 의 경우 0.058$)$
식 (1)을 시간 t에 대해 재배열하면 노내 체류시간이 다 음과 같이 계산된다[5].

$t=\frac{-1}{\lambda} \ln \left(1-\frac{(S)(A W)}{6.02 \times 10^{23} a_{i}\left(\sigma_{T} \phi_{T}+\sigma_{E} \phi_{E}+\sigma_{F} \phi_{F}\right)}\right)$

여기서, t : 노내 체류시간 $(\mathrm{sec})$
중성자 포획단면적 $(\sigma)$ 과 중성자속 $(\varphi)$ 의 아래첨자로 쓰 인 T, E, F는 각각 열중성자, 열외중성자, 속중성자를 의미한 다. 본 논문에서 노내 체류시간을 계산할 때 중성자속의 값 은 참고문헌 [5]의 제안값을, 중성자 포획단면적 값은 $\operatorname{Lin}[6]$ 의 제안값을 활용하였다(Table 4).

본 논문에서는 중성자속 노출기간 동안, 즉 주기 운전 
Doo Ho Lee : Evaluation of Core Residence Time of Fuel Cruds from Hanul Unit 1 Cycle 17

Table 4. Neutron Flux Values and Neutron Activation Cross Sections [5,6]

\begin{tabular}{ccc}
\hline Parameter & $\begin{array}{c}\text { Neutron Flux } \\
\left(\mathrm{n} / \mathrm{cm}^{2} \cdot \mathrm{s}\right)\end{array}$ & $\begin{array}{c}\text { Cross Sections for } \\
\left(\mathrm{cm}^{2}\right)\end{array}$ \\
\hline Thermal & $5.0 \times 10^{13}$ & 0 \\
\hline Epithermal & $2.325 \times 10^{14}$ & 0 \\
\hline Fast & $7.75 \times 10^{13}$ & $0.11 \times 10^{-24}$ \\
\hline
\end{tabular}

기간 동안 연료 크러드의 양이 선형적으로 증가된다는 가정 하에 해당 비방사능 값에 도달할 때까지의 소요시간을 노내 체류시간으로 계산하였다. 이 경우 처음부터 동일한 양의 크 러드가 중성자속에 노출되어 방사화된다는 가정보다는 노내 체류시간의 합리적인 계산이 가능해진다는 장점이 있다. 또 한 노내 체류시간을 예측할 때 ${ }^{58} \mathrm{Co}$ 과 ${ }^{59} \mathrm{Fe},{ }^{51} \mathrm{Cr}$ 의 비방사능 값보다는 ${ }^{60} \mathrm{Co}$ 또는 ${ }^{4} \mathrm{Mn}$ 의 비방사능 값이 훨씬 유용한데, 이 는 ${ }^{58} \mathrm{Co}$ 과 ${ }^{59} \mathrm{Fe}$ 등의 반감기가 한주기 운전기간보다 훨씬 짧 아서 주기 운전 개시 후 곧바로 포화되는 효과를 나타내기 때문이다[7]. 하지만 ${ }^{60} \mathrm{Co}$ 의 경우에는 모핵종인 ${ }^{59} \mathrm{Co}$ 의 크러 드 내 존재량이 낮아서 원소성분 검출이 거의 되지 않아 실 질적인 활용은 어려우므로, 본 논문에서는 ${ }^{54} \mathrm{Mn} / \mathrm{Fe}$ 의 비방 사능 값을 활용하여 크러드의 노내 체류시간을 계산하였다. Table 2 와 3 의 분석값 중에서는 동일 연료집합체, 동일 Span 에서 분석된 자료만을 활용하였는데, 이는 연료집합체 또는 Span별로 상대출력 및 비등율(boiling rate)이 달라지므로 크러드의 침적 및 체류시간이 달라질 것으로 예상되기 때문 이다. Table 5 에는 이렇게 구한 ${ }^{54} \mathrm{Mn} / \mathrm{Fe}$ 의 비방사능 값과 노 내 체류시간 계산결과를 나타냈다.

\section{3. 결론 및 고찰}

크러드의 노내 체류시간은 원전 설계 시에 예상 방사선 원항 계산 또는 일차계통 내 핵종 이송모델의 기초자료 등으 로 활용된다. Table 6에는 일례로써, 국내 원전 설계 시의 예 상 방사선원항 계산에 활용된 국외 원전의 크러드 노내 체 류시간을 보여주고 있다[8]. 크러드의 노내 체류시간에 대한 국내 원전의 자료는 전무한데, 이는 연료 크러드의 직접적 인 채취가 시도된 바 없었기 때문이다. 본 연구에서는 한울 1 호기 17 차 $\mathrm{O} / \mathrm{H}$ 시에 채취된 연료 크러드 시료를 활용하여
Table 5. ${ }^{54} \mathrm{Mn} / \mathrm{Fe}$ Specific Activities and Apparent Residence Times

\begin{tabular}{cccccc}
\hline F/A & Span & $\begin{array}{c}\mathrm{Fe} \\
(\mu \mathrm{g})\end{array}$ & $\begin{array}{c}{ }^{54} \mathrm{Mn} \\
(\mathrm{uCi})\end{array}$ & $\begin{array}{c}{ }^{54} \mathrm{Mn} / \mathrm{Fe} \\
(\mathrm{Ci} / \mathrm{g})\end{array}$ & $\begin{array}{c}\text { Residence Time } \\
(\text { Days })\end{array}$ \\
\hline $\mathrm{S} 50$ & $5 \mathrm{~B}$ & 34 & $1.83 \mathrm{E}-01$ & 0.005 & 35 \\
\hline $\mathrm{T} 65$ & $5 \mathrm{~B}$ & 16 & $1.93 \mathrm{E}-01$ & 0.012 & 81 \\
\hline
\end{tabular}

Table 6. Average and Maximum ${ }^{54} \mathrm{Mn} / \mathrm{Fe}$ Residence Times [8]

\begin{tabular}{cccccccccc}
\hline (Days) & $\begin{array}{c}\text { Plant } \\
\text { A }\end{array}$ & $\begin{array}{c}\text { Plant } \\
\text { B }\end{array}$ & $\begin{array}{c}\text { Plant } \\
\text { C }\end{array}$ & $\begin{array}{c}\text { Plant } \\
\text { D }\end{array}$ & $\begin{array}{c}\text { Plant } \\
\text { E }\end{array}$ & $\begin{array}{c}\text { Plant } \\
\text { F }\end{array}$ & $\begin{array}{c}\text { Plant } \\
\text { G }\end{array}$ & $\begin{array}{c}\text { Plant } \\
\text { H }\end{array}$ & $\begin{array}{c}\text { This } \\
\text { Study }\end{array}$ \\
\hline Ave. & 54 & 32 & 25 & 10 & 8 & 7 & - & 5 & 58 \\
\hline Max. & 390 & 104 & 116 & 38 & 11 & 19 & 84 & 118 & 81 \\
\hline
\end{tabular}

${ }^{54} \mathrm{Mn} / \mathrm{Fe}$ 비방사능 값과 이에 따른 노내 체류시간을 계산하 였다. 비록 본 연구에서 직접적으로 활용 가능한 크러드 시 료가 2개 밖에 되지 않아서 충분한 검증을 할 수는 없었으나 크러드의 노내 체류시간이 81일(1번 연소된 연료, T65) 35 일(2번 연소된 연료, S50) 수준임을 알 수 있었다. 이 계산값 은 Table 6의 국외 원전 크러드의 노내 체류시간 범주에 속 하였으나, 발전소별로 큰 차이를 보이는 요인에 대해서는 구 체적으로 확인할 수 없었다. 다만 본 논문에서는 ${ }^{54} \mathrm{Mn}$ 의 모 핵종인 ${ }^{4} \mathrm{Fe}$ 의 침적량이 일정한 비율로 증가되면서 방사화된 다는 가정 하에 노내 체류시간이 계산된 반면, Table 6의 국 외 원전 사례는 노내에서 처음부터 동일한 양의 ${ }^{54} \mathrm{Fe}$ 가 방사 화된다는 가정 하에 계산된 결과이므로 다소간의 차이는 예 상할 수 있다.

한울 1 호기의 계산결과 중 2 번 연소된 연료의 노내 체류 시간이 1 번 연소된 연료에서보다 작았던 것은 한울 1 호기 16 차 $\mathrm{O} / \mathrm{H}$ 시에 17 주기 재장전연료 89 다발 전체에 대해 시행한 연료 초음파 세정의 영향으로 풀이될 수 있다. 즉, 연료 초음 파 세정에 의해 $\mathrm{S} 50$ 에 침적되어 있던 크러드가 상당부분 제 거된 데에다, 이후 17 주기 연소기간 동안에는 신연료에 비하 여 상대출력이 더 작은 구간에 배치됨에 따라 크러드의 노내 침적 및 체류가 제한적으로만 이루어졌기 때문인 것으로 해 석될 수 있다. 다른 한편으로는 아연주입 운전에 의해 노내 크러드의 방출이 증가되면서 나타난 현상으로도 풀이될 수 있는데, Fig. 4에서처럼 한울1호기 17주기에 아연주입 운전 이 시작된 이후 원자로냉각재 중의 핵종농도가 증가된 경향 과도 일치한다. 즉, 아연주입 운전에 의해 노내 크러드 방출 이 증가되어 크러드의 노내 체류시간을 전반적으로 단축 


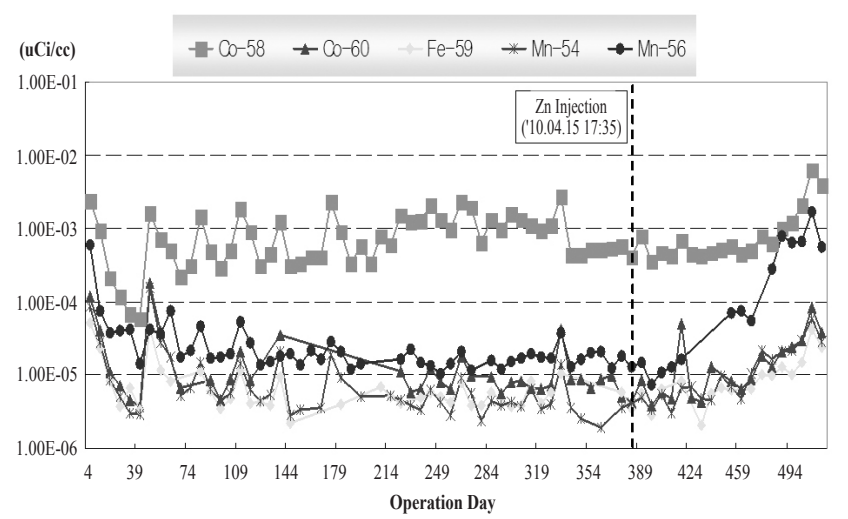

Fig. 4. Radionuclide Concentrations in RCS of Hanul Unit 1 Cycle 17.

시킨 효과가 나타났으며, 이러한 효과는 고출력 구간보다는 비등에 의한 침적 메커니즘이 적은 저출력 구간에서 높게 나 타났을 수 있다. 특히 아연주입에 의한 크러드의 노내 체류 시간 감소는 미국 Farley 2호기에서도 확인된 바 있으며[9], 이는 앞서 언급한 Fig. 4 와 같이 아연주입 운전이 일차계통 내 크러드 이동도에 영향을 줄 수 있음을 의미한다. 한편 한 울1호기의 ${ }^{54} \mathrm{Mn}$ 크러드의 노내 체류시간 결과(35 81일)를 보면 발전소 정지 시점에서의 연료 크러드의 방사화학적 조 성은 주기말 마지막 3 개월간의 운전기간 동안 결정될 것으 로 유추할 수 있다.

비록 63개의 연료 크러드 시료가 채취, 분석되어졌으나, 노내 체류시간의 계산이 가능한 시료는 2 개에 불과하여 충 분한 비교평가가 수행되지 못하였다. 향후에는 동일한 시료 를 대상으로 비파괴분석인 감마핵종 분석과 ICP-AES 분석을 순차적으로 시행하도록 분석계획에 반영할 필요가 있을 것 으로 판단된다.

\section{REFERENCES}

[1] D.H. Lister, "Activity Transport and Corrosion Processes in PWRs," Nucl. Energy, 32(2), pp. 103-114, 1993.

[2] Corrosion Product Releases in Light Water Reactors, EPRI, Palo Alto, CA: 1989. NP-6512.

[3] Impact of PWR Primary Chemistry on Corrosion Product Deposition on Fuel Cladding Surfaces, EPRI, Palo Alto, CA: 1997. TR-108783.
[4] Evaluation of Fuel Cladding Corrosion and Corrosion Product Deposits from Ulchin Unit 1 Cycle 17, EPRI, Palo Alto, CA: 2011. 1022898.

[5] Evaluation of Fuel Clad Corrosion Product Deposits and Circulating Corrosion Products in PWRs, EPRI, Palo Alto, CA, and Westinghouse Electric Company, Pittsburgh, PA: 2004. 1009951.

[6] C.C. Lin, "Radiochemistry in Nuclear Power Reactors," Nuclear Science Series, NAS-NS-3119, National Academy Press, Washington D.C., 1996.

[7] Activated Corrosion Product Formation in PWRs, EPRI, Palo Alto, CA: 2013. 3002000510.

[8] YGN 3\&4 Final Safety Analysis Report, KHNP, 1999.

[9] Evaluation of Zinc Addition to the Primary Coolant of PWRs, EPRI, Palo Alto, CA: 1996. TR-106358-V1. 